\title{
Usage of Reclaimed Asphalt Material in Stone Mastic Asphalt
}

\author{
Petr Hyzl, Ondrej Dasek (D), Iva Coufalikova, Michal Varaus, and Dusan Stehlik \\ Institute of Road Structures, Faculty of Civil Engineering, Brno University of Technology, Brno, CZ 60200, Czech Republic \\ Correspondence should be addressed to Ondrej Dasek; dasek.o@fce.vutbr.cz
}

Received 16 April 2019; Revised 19 June 2019; Accepted 21 July 2019; Published 4 August 2019

Guest Editor: Jose Norambuena-Contreras

Copyright (c) 2019 Petr Hyzl et al. This is an open access article distributed under the Creative Commons Attribution License, which permits unrestricted use, distribution, and reproduction in any medium, provided the original work is properly cited.

\begin{abstract}
The paper focuses on the issue of using reclaimed asphalt (RA) in asphalt mixtures used for highly traffic-loaded asphalt pavements-in asphalt mixtures of the stone mastic asphalt (SMA) type. It is a skeleton-type mixture, where the traffic load is bore by a skeleton of coarse aggregates bonded with mastic (i.e., bitumen and fine aggregates). It is therefore essential to pay close attention to the properties of this coarse aggregate. Higher demands on properties of the aggregate are probably due to the fact that RA is not currently being used in SMA-type mixtures. Most standards do not allow usage of RA in this type of mixtures. Given that traffic load of road networks is constantly increasing, the ratio of SMA-type asphalt mixtures also increases in the road network. This paper presents results of 5-year research focused on the possibility of using RA in SMA-type asphalt mixtures. This included laboratory design of these mixtures with various dosages and types of RA. Their empirical and functional properties were verified. Based on the positive results of the laboratory testing, a test section was subsequently constructed using several variants of the mixtures containing up to $50 \%$ of RA. This test section is regularly being monitored, and despite very intense traffic load, there are no failures apparent after 2 and half years of operation. Based on the laboratory research and subsequent construction and monitoring of a test section, it can be said that RA can be used in SMA-type mixtures without any negative impacts on functional properties or mixture lifetime.
\end{abstract}

\section{Introduction}

Based on the European Asphalt Pavement Association (EAPA), the total length of the European road network is more than 5 million kilometres, out of which $66,700 \mathrm{~km}$ is classified as highways. Vast majority of these roads have asphalt surface [1]. Annual production of the total number of 4700 European asphalt mixing plants is approximately 282.5 million tons of the asphalt mixture [2]. Given the limited amount of natural resources, it is in long term essential to use materials already built-in to current road constructions, as much as possible. Literature [3] shows that the European road network contains approximately 950 billion tons of asphalt mixtures.

Using various recycling methods of these building materials, it is possible to maintain the natural material resources (aggregates and bitumen) and decrease the energy and economical demands of construction works. Given the fact that the cost of basic components for the manufacture of asphalt mixtures constantly increases in long term, the use of reclaimed asphalt (RA) in asphalt mixture manufacturing is advantageous from the economical perspective as well $[4,5]$. It is not just the cost of the aggregate but also the cost of the bitumen, which is the most expensive component in the asphalt mixture.

RA is already used in some countries routinely in asphalt concrete (AC) mixtures (dense graded), even in relatively high ratio, often above $50 \%$ [6-8]. In contrast, use of RA is not very common in mixtures of the stone mastic asphalt (SMA) type. It is especially because these mixtures have high demands on aggregate gradation, which is gap graded and usually dense gradation of RA often does not satisfy this gapgraded gradation requirement. Nevertheless, there are studies which describe high ratios of RA in SMA mixtures. Vast majority of countries, however, currently do not allow the use of RA in SMA mixtures.

This paper, based on laboratory research and realization using a test section with various mixture variants, shows that usage of SMA mixtures with a certain ratio of RA is well possible in practice without any negative impacts on functional parameters and lifetime of the layer. 
The study [9] focused on determination of optimum content of cellulose fibres in RA in the SMA asphalt mixture. RA ratios used were $0 \%, 8 \%, 16 \%$, and $24 \%$. Based on the results of the Marshall stability, rutting test, and indirect tensile strength, it was found that the optimum ratio of RA is $16 \%$.

The study [10] included comparison of resistance against deformation of stone mastic asphalt with various RA contents ( $0 \%$ to $50 \%)$. As the RA content increased, the resistance of the SMA mixtures against deformation also increased, which was affected by polymer-modified bitumen contained in the RA. This study assumed dosages of RA to the SMA mixture up to $50 \%$; however, this only included mixtures prepared in a laboratory. Similar issue is dealt with in the study [11], where stone mastic asphalt with RA content up to $30 \%$ and AC with RA content up to $50 \%$ were designed. Results of laboratory functional tests (stiffness, fatigue, and rutting) proved little differences between the properties of asphalt mixtures with low and high RA content.

The issue of adding RA into SMA mixtures was dealt with as part of the project [12] solved not just by representatives of the technological institute but also by a representative of an investor, and the conclusion was recommendation of adding $30 \%$ of RA into all SMA mixtures.

\section{Scope}

Scope of this paper is to summarize and describe the results of a 5-year research focused on the possibilities of using RA in asphalt mixtures of the stone mastic asphalt (SMA) type, which is, thanks to its skeleton, used in most traffic-loaded asphalt pavements (highways, etc.). The paper also introduces the concept of high dosage of RA in SMA (up to $50 \%$ ), which is currently a relatively new technology with very little experiences worldwide. The paper describes a design of an SMA mixture with aggregate gradation up to $11 \mathrm{~mm}$ (SMA 11) with various dosages of RA ( $0 \%$ to $50 \%$ ), results of laboratory tests of these mixtures, and realization of test sections including evaluation of lifetime of these sections after 2.5 years in operation. Another goal was determination of parameters for standards and regulations with respect to RA dosages in SMA.

\section{Methods}

Three tests were chosen to assess the mechanical properties of SMA mixtures: the wheel tracking test was used to determine rutting resistance (EN 12697-22), the two-point bending test was used to determine the stiffness (EN 1269726, Annex A), and the thermal stress-restrained specimen test (TSRST) with a temperature decrease was used to determine low-temperature properties (EN 12697-46).

3.1. Wheel Tracking Test. The wheel tracking test was performed according to EN 12697-22 method B (wheel tracking test with a small size device in air) under constant temperature $\left(50^{\circ} \mathrm{C}\right.$ and $\left.60^{\circ} \mathrm{C}\right)$. Dimensions of slabs were $260 \mathrm{~mm} \times 320 \mathrm{~mm}$ and $50 \mathrm{~mm}$ high. The slabs were compacted in a laboratory by using a compactor with a roller running on vertical sliding steel plates. Resistance to permanent deformation was assessed by proportional rut depth at $10^{4}$ cycles $\left(\mathrm{PRD}_{\mathrm{AIR}}\right)$, and wheel tracking slope was calculated as the average rate at which the rut depth increases with repeated passes $\left(\mathrm{WTS}_{\mathrm{AIR}}\right)$.

3.2. Stiffness Test. Stiffness of the individual mixtures was determined based on the EN 12697-26 using the two-point bending test on trapezoidal-shaped specimens performed at $15^{\circ} \mathrm{C}$ and a load frequency of $5,10,15,20$, and $25 \mathrm{~Hz}$. The slabs were compacted similarly to the wheel tracking test. The degree of compaction of slabs was between $99 \%$ and 101\%. Trapezoidal-shaped specimens were cut from slabs using the sliding table circular saw. For the purposes of the stiffness modulus test, 15 trapezoidal-shaped specimens were produced from each mixture.

3.3. Low-Temperature Properties. The low-temperature properties were determined according to EN 12697-46. The critical temperature and the tensile stress in the tested specimen was determined using a uniaxial tension testthermal-stress restrained specimen test (TSRST). When a crack forms by cooling of the prismatic beam $(50 \mathrm{~mm} \times 50 \mathrm{~mm} \times 200 \mathrm{~mm})$ at a constant rate of $10^{\circ} \mathrm{C} / \mathrm{h}$ from the initial temperature, the given specimen is restricted from contracting, i.e., with no longitudinal strain.

3.4. Asphalt Binder Tests. Binders were extracted from the asphalt mixtures manufactured for the test sections, and these were subjected to the multiple stress creep and recovery (MSCR) test in accordance with EN 16659 at a temperature $60^{\circ} \mathrm{C}$ in a dynamic shear rheometer. The main aim of this test was to verify the functionality of the rejuvenators and modification additives and set standard requirements.

\section{Materials}

4.1. Aggregate. The crushed split aggregates used in this study came from the Zbečno quarry, and the fractions used were $0 / 2 \mathrm{~mm}, 2 / 5 \mathrm{~mm}, 4 / 8 \mathrm{~mm}$, and $8 / 11 \mathrm{~mm}$ and limestone filler, which satisfied the requirements of the EN 13043 standard.

4.2. Asphalt Binder. Polymer-modified bitumen PMB 45/8055 was used for the manufacture of the asphalt mixtures. Basic properties of this bitumen are given in Table 1.

4.3. Reclaimed Asphalt (RA). Two types of RA were used for the manufacture of SMA:

(a) Standard RA was obtained from milling of asphalt layers containing paving (nonmodified) bitumen. The age of the milled layers from the 1st class road was 8 years. Such RA is hereafter referred to as "RAP." Content of the asphalt binder determined by extraction was found to be $5.16 \%$ (Table 2). 
TABLE 1: Basic parameters of PMB 45/80-55.

\begin{tabular}{lcc}
\hline Test & Determined values & Requirements of the EN 14023 standard \\
\hline Needle penetration in accordance with EN 1426 & $65(0.1 \mathrm{~mm})$ & $45-80(0.1 \mathrm{~mm})$ \\
Softening point in accordance with EN 1427 & $61.6^{\circ} \mathrm{C}$ & Minimum $55^{\circ} \mathrm{C}$ \\
Elastic recovery in accordance with EN 13398 & $86 \%$ & Minimum $60 \%$ \\
\hline
\end{tabular}

TABLE 2: Basic properties determined for reclaimed binder from RA of gradation 0/11 mm (RAP) for SMA 11.

\begin{tabular}{lc}
\hline Test & $\begin{array}{c}\text { Determined } \\
\text { values }\end{array}$ \\
\hline $\begin{array}{l}\text { Needle penetration in accordance with EN 1426 } \\
\text { Softening point in accordance with EN 1427 }\end{array}$ & $\begin{array}{c}24.7 \mathrm{~mm}) \\
\text { Dynamic viscosity at } 135^{\circ} \mathrm{C} \text { in accordance }\end{array}$ \\
$\begin{array}{l}\text { with EN 13302 } \\
\text { Elastic recovery in accordance with EN 13398 }\end{array}$ & $0.81 \mathrm{~Pa} \cdot \mathrm{s}$ \\
PG grade & $7 \%$ \\
$\begin{array}{l}\text { Fraass breaking point in accordance } \\
\text { with EN } 12593\end{array}$ & $-2^{\circ} \mathrm{C}$ \\
\hline
\end{tabular}

(b) RA was obtained by milling wearing course, made from SMA mixtures with polymer-modified bitumen. The age of the milled surface layer from the motorway was 9 years. Such RA is hereafter referred to as "RAP SMA." Asphalt binder content determined by extraction was found to be $6.4 \%$ (Table 3 ).

Dynamic shear rheometer (DSR) was used to compare the functional properties of reclaimed binders made from both of the RAs. Black diagram (relationship between complex shear modulus and phase angle) is given in Figure 1.

The curve shows a specific wavy trend of the Black diagram of the modified bitumen in RAP SMA, which differs from a Black diagram of a nonmodified bitumen especially in the area of low complex shear modulus values. The modified RAP SMA bitumen has a lower value of phase angle at the equivalent value of complex shear modulus.

Both RAs were crushed to gradation $0 / 11 \mathrm{~mm}$ prior to use. Aggregate gradation of both RAs is compared in Figure 2. This graph shows a more gap-graded curve in case of RAP SMA, which was subsequently (due to favourable gradation) used in the mixture with the highest dosage of RA.

4.4. Other Materials Used. To limit binder drainage, $0.3 \%$ of cellulose fibres S-CEL $7 \mathrm{G}$ was added to all asphalt mixtures. To improve binder adhesion to the aggregate, the Addibit L300 additive was added to all the mixtures $(0.2 \%$ of binder weight). Storflux rejuvenator was applied in order to soften the aged asphalt binder contained in the RA.

4.5. Laboratory Designs of SMA 11 with RA. When designing SMA 11 mixtures with various RA ratios in a laboratory (Marshall design with requirements specified in EN 131085), the main aim was to set (if possible) equivalent sieve size
TABLE 3: Basic properties determined for reclaimed binder from RA of gradation 0/11 mm (RAP SMA) for SMA 11.

\begin{tabular}{lc}
\hline Test & $\begin{array}{c}\text { Determined } \\
\text { values }\end{array}$ \\
\hline $\begin{array}{l}\text { Needle penetration in accordance with EN 1426 } \\
\text { Softening point in accordance with EN 1427 }\end{array}$ & $69.1 \mathrm{~mm})$ \\
$\begin{array}{l}\text { Dynamic viscosity at } 135^{\circ} \mathrm{C} \text { in accordance } \\
\text { with EN 13302 }\end{array}$ & $1.23 \mathrm{~Pa} \cdot \mathrm{s}$ \\
Elastic recovery in accordance with EN 13398 & $43 \%$ \\
PG grade & $76-4$ \\
Fraass breaking point in accordance & $-3^{\circ} \mathrm{C}$ \\
with EN 12593 & \\
\hline
\end{tabular}

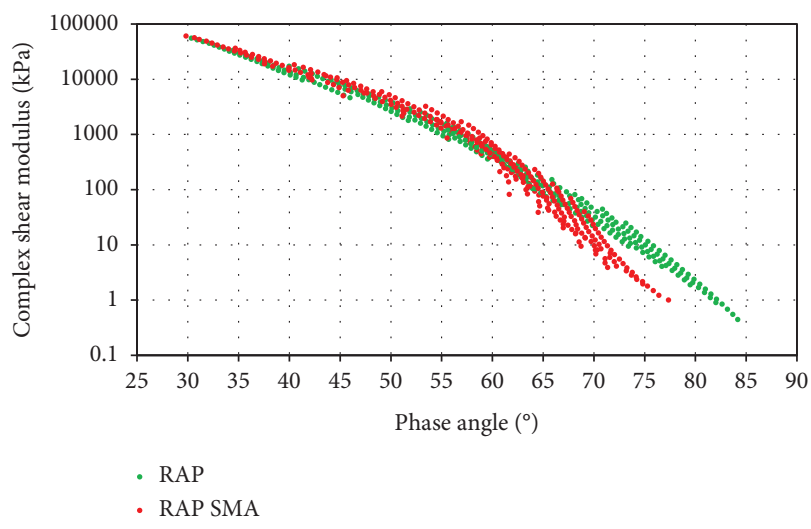

FIGURE 1: Black diagram-reclaimed binders from used RA.

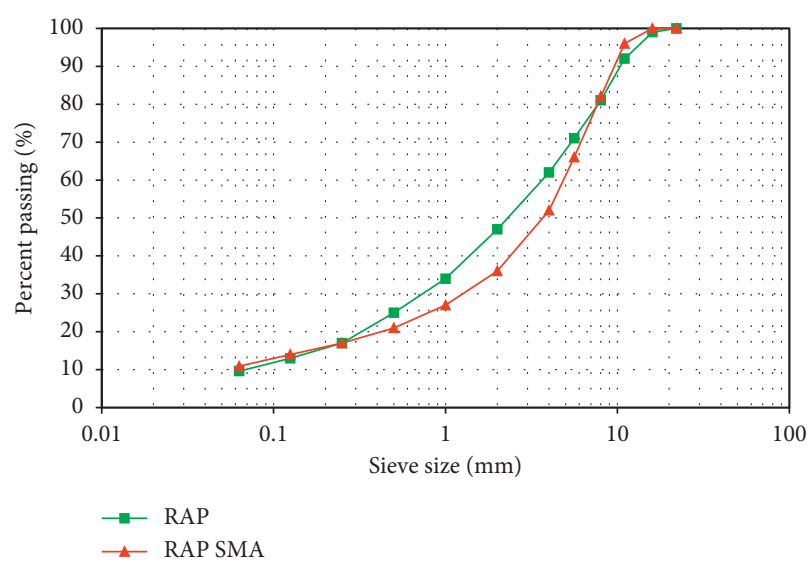

FIGURE 2: Sieve size distribution of used RAs.

distribution and final overall content of asphalt binders in the individual mixtures so that the designed mixtures could be compared with one another during subsequent functional laboratory tests and on test sections. Binder optimum was 
chosen based on evaluation of the results of air void content for the individual laboratory-prepared sets with a binder content of $6.3 \%, 6.5 \%$, and $6.7 \%$, which are not further mentioned in this paper in order to keep the text concise.

In particular, an optimization of six variants of asphalt mixtures of the SMA 11 type was performed:

(a) SMA 11 with $0 \%$ RA was used as a reference mixture

(b) SMA 11 with 10\%, 20\%, and 30\% "RAP"

(c) SMA 11 with $30 \%$ and 50\% "RAP SMA"

Overall optimum ratio of asphalt binder in all mixtures was $6.5 \%$. Binder contained in the RA was included in this overall binder content. Binder content in RA was always subtracted from the added amount of new polymer-modified bitumen PMB 45/80-55. Table 4 shows composition of the individual mixture variants, and Figure 3 provides the sieve size distribution of the final mixture designs. In case of the design of the SMA mixtures, the rejuvenating additive Storflux (producer Storimpex Group) was used both for the laboratory design and for the trial section. The recommended dosing by the producer was $20 \mathrm{~kg}$ of Storflux per 1 ton RA.

\section{Results and Discussion}

5.1. Wheel Tracking Test. Wheel tracking test results determined at temperatures of $50^{\circ} \mathrm{C}$ and $60^{\circ} \mathrm{C}$ are given in Table 5 and Figure 4. The standard deviation values are shown in brackets. Upon increasing the test temperature from $50^{\circ} \mathrm{C}$ to $60^{\circ} \mathrm{C}$, the value of parameters $\mathrm{WTS}_{\mathrm{AIR}}$ and $\mathrm{PRD}_{\mathrm{AIR}}$ increased. Resistance against deformation of all mixtures was similar, and increasing the ratio of RA does not significantly worsen the resistance of the SMA mixture against permanent deformation. All the compared asphalt mixtures satisfied the required resistance against deformation (the maximum value of parameter $\mathrm{PRD}_{\mathrm{AIR}}$ is $5.0 \%$, and the maximum value of parameter $\mathrm{WTS}_{\mathrm{AIR}}$ is $0.07 \mathrm{~mm} / 10^{3}$ cycles at a temperature of $50^{\circ} \mathrm{C}$ ).

5.2. Stiffness. Stiffness modulus results are given in Table 6 and graphically assessed in Figure 5.

Based on the assessment of the above provided results for determination of stiffness modulus, it can be said that stiffness moduli of all variants lie in a relatively narrow range and there are only relatively small differences between them. In case of the mixture with standard RA (RAP), the values of stiffness modulus at a temperature of $15^{\circ} \mathrm{C}$ and load frequency of $10 \mathrm{~Hz}$ ranged between $6434 \mathrm{MPa}$ and $7207 \mathrm{MPa}$. Mixtures with RA from the SMA mixture (RAP SMA) under same conditions showed stiffness moduli between $6683 \mathrm{MPa}$ and $7321 \mathrm{MPa}$, i.e., slightly higher values. Therefore, if a rejuvenator is used to soften an aged RA binder, there is no excessive increase in stiffness of the SMA mixtures with a high RA content.

5.3. Low-Temperature Properties. The determined parameters of maximum tensile strength and temperature of the test specimen upon crack formation are summarized in Table 7.
The resulting maximum tensile strength upon crack formation is in case of all tested mixture variants practically identical when taking into account uncertainties of the measurement. Similarly, the tested specimen temperatures upon frost crack appearance are very similar. Variants with RA from SMA (RAP SMA) show slightly better results, which can be explained by the presence of polymer-modified bitumen in the RA. It can therefore be deduced that using higher dosage of RA does not lead to worse low-temperature behaviour of SMA mixtures (assuming usage rejuvenator to soften the aged binder in RA).

5.4. Test Section. During September 2016, a test section was built in the Czech Republic based on the above described laboratory research. This section included a total of six variants of wearing layers, created from SMA 11 mixture with two types of RA (RAP and RAP SMA) and their various dosages (0\% to 50\%). For comparison, a section containing unmodified paving bitumen 50/70 was built (Section 7). No problems were encountered during the manufacture of all asphalt mixture variants in the asphalt mixing plant (using parallel drum), rejuvenator dosage or subsequent laying, and compaction of the mixtures with no negative impact of added RA on the asphalt mixtures.

Drilled cores from all subsections were sampled in 2017. Subsequently, mixture analyses and functional tests were performed on the obtained binders, especially to verify functionality of the rejuvenators and set the standard requirements. In the meantime, regular monitoring of the test section state was started, which is done by visual inspection.

Below are results of the authors' work, where comparison was made between the sampled drilled cores from all the sections, with the aim to set a criterion for the maximum content and type of RA in SMA mixtures based on standard regulations.

Samples of SMA were taken for subsequent laboratory analyses of all mixture variants. Asphalt binder was reclaimed from these mixtures for performing basic empirical tests and rheological measurements, and also sieve analysis of the aggregate was performed.

Rheological measurements were performed in order to assess the effect of differences between rheological behaviour of reclaimed binders from mixtures, containing both of the used RA types. Because these mixtures underwent coating process and were approximately one year in operation in a pavement, the authors consider the results very important for determination of standard requirements.

Aggregate sieve analyses were performed especially to assess the effect of dosage of standard RA (RAP) with dense-graded sieve size distribution and RA from SMA mixture (RAP SMA) with gap-graded sieve size distribution curve on the overall gradation of the asphalt mixture.

A dynamic shear rheometer Kinexus was used to determine the rheological properties of the reclaimed binders. In particular, the MSCR test (multiple stress 
TABLE 4: Composition of the individual SMA 11 mixture variants with various ratios of RA (RAP and RAP SMA).

\begin{tabular}{|c|c|c|c|c|c|c|}
\hline \multirow{2}{*}{ Mixture } & \multicolumn{6}{|c|}{ SMA 11} \\
\hline & $0 \%$ RAP & $10 \%$ RAP & $20 \%$ RAP & $30 \%$ RAP & $30 \%$ RAP SMA & $50 \%$ RAP SMA \\
\hline Filler (\%) & 10.5 & 9.5 & 8.0 & 7.5 & 6.5 & 3.7 \\
\hline Fraction $0 / 2(\%)$ & 15.0 & 10.0 & 6.0 & 3.0 & 3.0 & - \\
\hline Fraction $2 / 5(\%)$ & 18.0 & 18.0 & 16.0 & 8.0 & 9.5 & 1.0 \\
\hline Fraction $4 / 8(\%)$ & 8.0 & 8.0 & 6.0 & 9.0 & 8.5 & 7.0 \\
\hline Fraction $8 / 11(\%)$ & 48.5 & 44.5 & 44.0 & 42.5 & 42.5 & 38.3 \\
\hline RAP (\%) & - & 10.0 & 20.0 & 30.0 & - & - \\
\hline RAP SMA (\%) & - & - & - & - & 30.0 & 50.0 \\
\hline S-CEL 7G (\%) & 0.3 & 0.3 & 0.3 & 0.3 & 0.3 & 0.3 \\
\hline Total binder content (\%) & 6.5 & 6.5 & 6.5 & 6.5 & 6.5 & 6.5 \\
\hline Colflex 45/80-55 (new binder) (\%) & 6.5 & 6.0 & 5.5 & 5.0 & 4.6 & 3.3 \\
\hline Addibit L300 (\%) & 0.2 & 0.2 & 0.2 & 0.2 & 0.2 & 0.2 \\
\hline Air void content (\%) & 3.8 & 3.6 & 3.7 & 3.6 & 3.6 & 3.6 \\
\hline Maximum specific gravity $\left(\mathrm{kg} / \mathrm{m}^{3}\right)$ & 2563.8 & 2564.8 & 2537.9 & 2545.0 & 2567.2 & 2579.0 \\
\hline Bulk specific gravity $\left(\mathrm{kg} / \mathrm{m}^{3}\right)$ & 2468.1 & 2473.1 & 2444.4 & 2452.6 & 2475.0 & 2490.8 \\
\hline Voids in mineral aggregates (\%) & 19.5 & 19.3 & 19.3 & 19.3 & 19.4 & 19.3 \\
\hline Voids filled by bitumen (\%) & 81 & 82 & 81 & 81 & 81 & 82 \\
\hline Total binder content (\%-vol.) & 15.7 & 15.8 & 15.6 & 15.6 & 15.8 & 15.9 \\
\hline
\end{tabular}

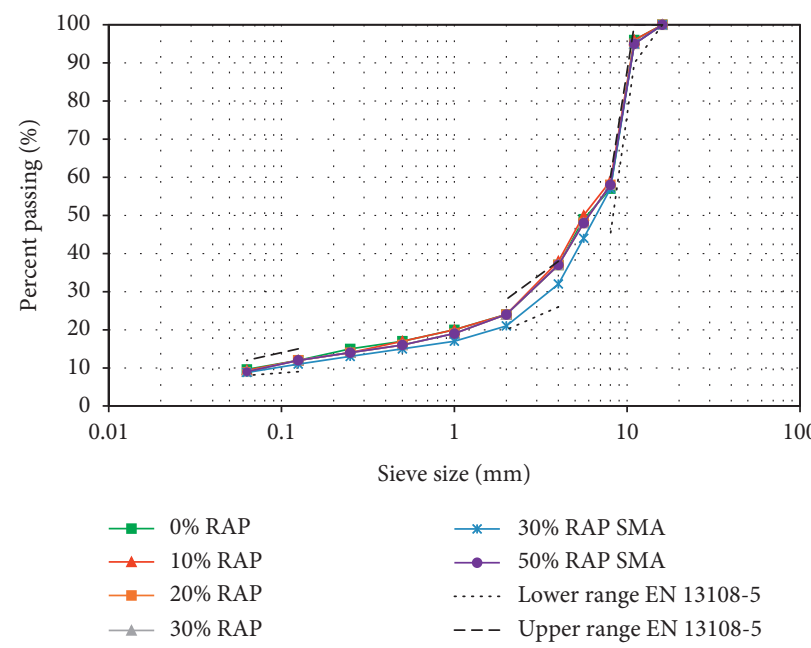

Figure 3: Sieve size distribution of the individual variants of the designed SMA 11 mixtures with various ratios and both types of RA.

TABLE 5: Determined parameters of resistance against permanent deformation of SMA 11 mixture.

\begin{tabular}{|c|c|c|c|c|}
\hline Mixture & $\mathrm{WTS}_{\mathrm{AIR}}\left(\mathrm{mm} / 10^{3}\right.$ cycles $)$ & $\mathrm{PRD}_{\mathrm{AIR}}(\%)$ & $\mathrm{WTS}_{\mathrm{AIR}}\left(\mathrm{mm} / 10^{3}\right.$ cycles $)$ & $\mathrm{PRD}_{\text {AIR }}(\%)$ \\
\hline Temperature $\left({ }^{\circ} \mathrm{C}\right)$ & 50 & & 60 & \\
\hline SMA $110 \%$ RAP & $0.012(0.001897)$ & $1.8(0.366824)$ & - & - \\
\hline SMA 11 10\% RAP & $0.018(0.002898)$ & $2.0(0.288097)$ & - & - \\
\hline SMA $1120 \%$ RAP & $0.028(0.002530)$ & $2.3(0.209762)$ & - & - \\
\hline SMA $1130 \%$ RAP & $0.026(0.002191)$ & $1.7(0.244949)$ & $0.048(0.002608)$ & $2.1(0.275681)$ \\
\hline SMA $1130 \%$ RAP SMA & $0.026(0.001265)$ & $1.6(0.260768)$ & $0.049(0.00228)$ & $2.6(0.126491)$ \\
\hline SMA $1150 \%$ RAP SMA & $0.019(0.002000)$ & $2.0(0.192354)$ & $0.046(0.003578)$ & $3.0(0.289828)$ \\
\hline
\end{tabular}

creep and recovery test) was performed in accordance with the EN 16659, which also allows assessing and differentiating the degree of binder modification. This issue is described in detail in [13]. The table below shows test results of selected binder variants. The binders below were chosen with the aim to determine the parameters for the standard:

(a) From Section 1, the "reference mixture", containing modified asphalt and no reclaimed asphalt material (b) From Section 5, a mixture containing polymer-modified bitumen PMB 45/80-55 and 30\% RAP SMA

(c) From Section 7, for comparison, mixture containing paving bitumen 50/70 and no reclaimed asphalt material

The results of shear strain during multiple stress creep and recovery test (Figure 6) and the obtained parameters (Table 8) show that binders recovered from Sections 1 and 5 


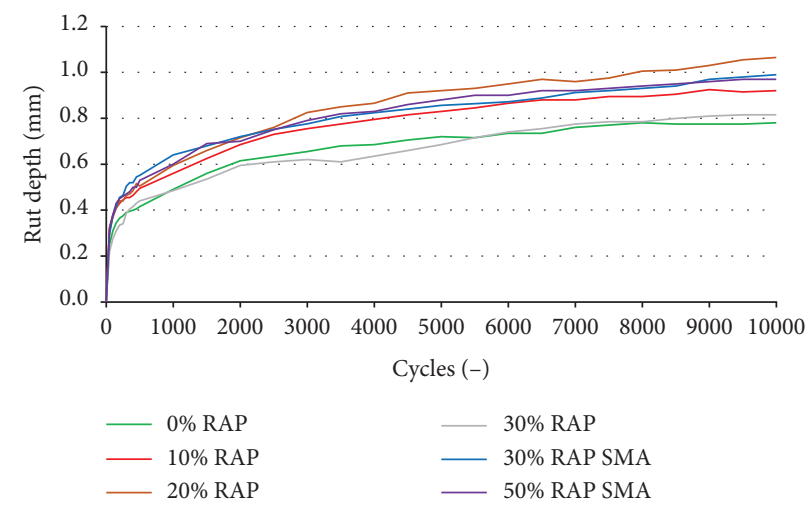

FIgURE 4: Course of the wheel tracking test at a temperature of $50^{\circ} \mathrm{C}$.

TABLE 6: Stiffness of SMA 11 mixture variants with various RA ratios (RAP and RAP SMA).

\begin{tabular}{|c|c|c|c|c|c|}
\hline \multirow{2}{*}{ Mixture } & \multicolumn{5}{|c|}{ Stiffness modulus $(\mathrm{MPa})$ at $15^{\circ} \mathrm{C}$ and load frequency } \\
\hline & $5 \mathrm{~Hz}$ & $10 \mathrm{~Hz}$ & $15 \mathrm{~Hz}$ & $20 \mathrm{~Hz}$ & $25 \mathrm{~Hz}$ \\
\hline SMA $110 \%$ RAP & $6405(52.4)$ & $7082(36.4)$ & $7492(35.0)$ & $7835(34.8)$ & $8156(34.8)$ \\
\hline SMA 11 10\% RAP & $5765(34.9)$ & $6434(26.4)$ & $6864(39.7)$ & $7178(34.8)$ & $7443(38.5)$ \\
\hline SMA $1120 \%$ RAP & $6235(42.7)$ & $6923(23.5)$ & $7400(51.3)$ & $7736(38.4)$ & $8047(38.2)$ \\
\hline SMA $1130 \%$ RAP & $6467(24.8)$ & $7207(45.7)$ & $7703(32.6)$ & $8075(21.1)$ & $8393(46.2)$ \\
\hline SMA $1130 \%$ RAP SMA & $6076(19.4)$ & $6683(38.1)$ & $7083(48.0)$ & $7382(30.0)$ & $7868(35.0)$ \\
\hline SMA $1150 \%$ RAP SMA & $6691(37.1)$ & $7321(30.3)$ & $7760(38.0)$ & $8111(35.2)$ & $8521(43.2)$ \\
\hline
\end{tabular}

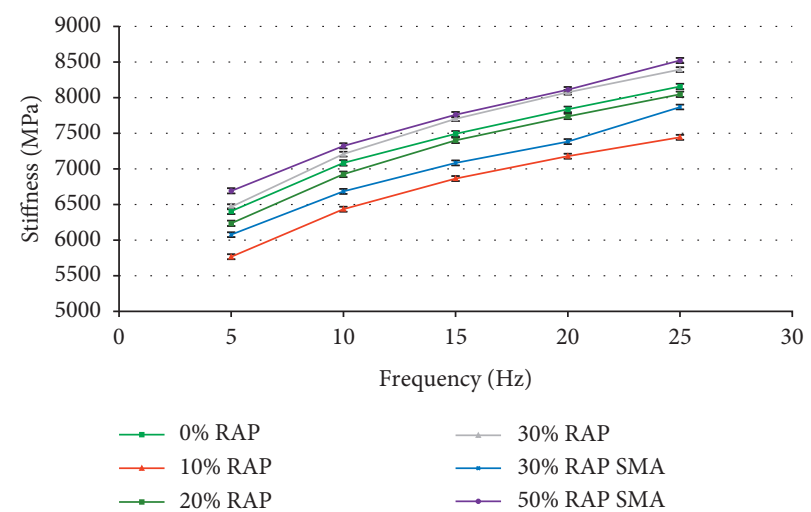

FIgURE 5: Stiffness of the individual SMA 11 mixture variants with various ratios and both types of RA.

TABLE 7: Low-temperature parameters of SMA 11 mixtures with various ratios of RA (RAP and RAP SMA).

\begin{tabular}{|c|c|c|}
\hline \multirow{2}{*}{ Mixture } & \multicolumn{2}{|c|}{ Low-temperature properties based on EN 12697-46 } \\
\hline & Maximum tensile strength (MPa) & Temperature at crack formation $\left({ }^{\circ} \mathrm{C}\right)$ \\
\hline SMA $110 \%$ RAP & $3.60(0.228)$ & $-22.9(0.638)$ \\
\hline SMA 11 10\% RAP & $4.08(0.207)$ & $-21.9(0.603)$ \\
\hline SMA $1120 \%$ RAP & $3.72(0.273)$ & $-21.0(0.566)$ \\
\hline SMA $1130 \%$ RAP & $4.04(0.236)$ & $-21.6(0.579)$ \\
\hline SMA $1130 \%$ RAP SMA & $4.24(0.361)$ & $-24.4(0.603)$ \\
\hline SMA $1150 \%$ RAP SMA & $3.84(0.305)$ & $-23.1(0.609)$ \\
\hline
\end{tabular}

(i.e., with $0 \%$ of reclaimed asphalt material and 30\% RAP SMA) behave very similarly, unlike bitumen from Section 7 (i.e., 50/70) which behaves differently. Given the fact that nonmodified paving bitumen was used in Section 7 , the lowest value of $J_{\mathrm{nr} 3,2}$ and highest value of $R_{3,2}$ were achieved.
Figure 7 shows results of sieve analyses of the aggregate from all asphalt mixtures. Sieve size distribution of recovered aggregates from all mixtures lies in a relatively narrow range. Given the particular drops on the standardrequired sieves, it was determined that the requirements of 


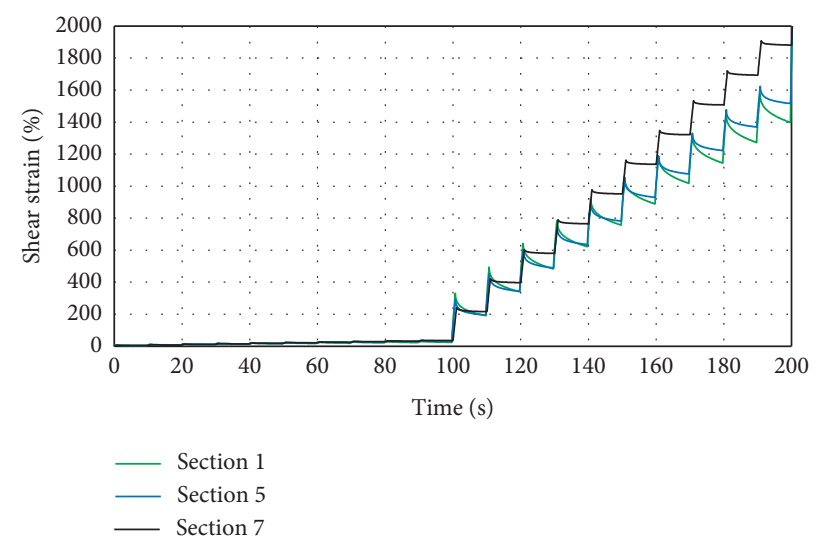

Figure 6: Progress of multiple stress creep and recovery test for chosen recovered bitumens.

TABLE 8: Results of multiple stress creep and recovery test according to EN 16659 for selected recovered binders.

\begin{tabular}{lcccccc}
\hline \multirow{2}{*}{ Binder recovered from } & \multicolumn{5}{c}{ MSCR test results } \\
& $J_{\mathrm{nr} 0,1}\left(\mathrm{kPa}^{-1}\right)$ & $J_{\mathrm{nr} 3,2}\left(\mathrm{kPa}^{-1}\right)$ & $J_{\mathrm{nr}, \mathrm{diff} 3,2-0,1}(\%)$ & $R_{0,1}(\%)$ & $R_{3,2}(\%)$ & $R_{\mathrm{diff} 3,2-0,1}(\%)$ \\
\hline Section 1 & 0.24 & 0.43 & 75.77 & 71.46 & 54.52 \\
Section 5 & 0.32 & 0.46 & 42.72 & 54.96 & 41.78 \\
Section 7 & 0.35 & 0.58 & 65.63 & 35.82 & 12.18 & 23.71 \\
\hline
\end{tabular}

$J_{\mathrm{nr}} \ldots$ is the nonrecoverable creep compliance (at two shear stresses: $0.1 \mathrm{kPa}$ and $3.2 \mathrm{kPa}$ ) in $\mathrm{kPa}^{-1} ; R$ is the average percent recovery in $\%$.

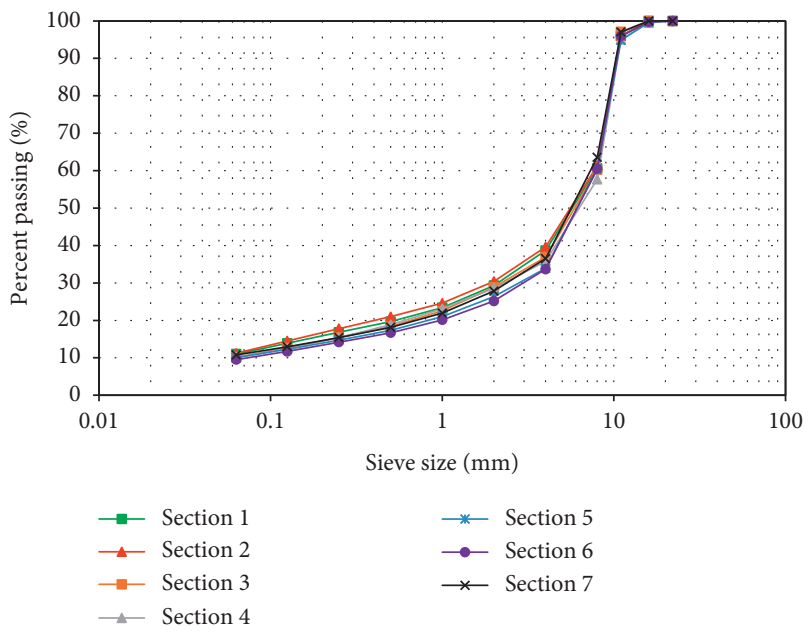

FIGURE 7: Sieve size distribution of recovered aggregates from test sections.

the standard were satisfied with regard to aggregate gradation of mixture.

Upon closer analysis of the sieve size distribution curves, it can be seen that mixtures where RAP SMA was used show better results (more gap graded) of the sieve size distribution curve, which is closer to gradation of SMA-type asphalt mixtures.

\section{Conclusions}

The paper presents and analyzes results of a 5-year research focused on the possibility of using the reclaimed asphalt material (in a dosage up to 50\%) in stone mastic asphalt
(SMA), which is, thanks to its skeleton structure, used predominantly in very heavily traffic-loaded pavements (highways, etc.). For concluding, the following are considered:

(i) The abovementioned results (stiffness, resistance against permanent deformations, and low-temperature properties) of the individual laboratory-prepared SMA mixtures with various dosages of the reclaimed asphalt material (10\% to 50\%) and comparison with reference mixture with no reclaimed asphalt material

(ii) Trouble-free real manufacture of these mixtures in an asphalt mixing plant and subsequent laying of all variants of SMA mixtures in the test section

(iii) Analysis of properties of the taken asphalt mixtures and recovered asphalt binders, which were in operation and performed well with no issues until now despite being heavily traffic loaded

Based on the above results, it can be said that it is possible to use the reclaimed asphalt material in SMA-type mixtures without any negative impacts on functional properties or layer lifetime. Based on the above results and experience, the authors currently recommend change of the standard (in particular proposal of national parameters in standard EN 13 108-5) regarding content of the reclaimed asphalt material in SMA-type mixtures. The current prohibition of adding the reclaimed asphalt material to SMA-type mixtures is replaced with possibility of adding the processed reclaimed asphalt material in the ratio up to $20 \%$, given the reclaimed asphalt material must be obtained by separate milling of wearing 
course of the pavement made from the SMA-type mixture (i.e., with modified asphalt binder-RAP SMA). Proper processing means not just precrushing of the material to the required fraction, roofing of RA deposits, its separation by milling layer by layer, but especially usage of rejuvenators for restoration of properties of the aged bitumen in the reclaimed asphalt material.

\section{Data Availability}

The data used to support the findings of this study are included within the article.

\section{Conflicts of Interest}

The authors declare that there are no conflicts of interest.

\section{Acknowledgments}

This paper has been worked out under the project TA04031328 "Recycling of stone mastic asphalts and development of special celullose fibres for this type of asphalt mixtures" and project no. LO1408 "AdMaS UP-Advanced Materials, Structures and Technologies," supported by Ministry of Education, Youth and Sports under the "National Sustainability Programme I.”

\section{References}

[1] D. Cihlářová, I. Fencl, S. Cápayová, and P. Pospíšil, "Use of adhesion promoters in asphalt mixtures," Slovak Journal of Civil Engineering, vol. 26, no. 1, pp. 19-24, 2018.

[2] "EAPA statement," https://eapa.org/asphalt/.

[3] EAPA Position Paper, Asphalt the 100\% Recyclable Construction Product, European Asphalt Pavement Association, Brussels, Belgium, 2014, https://eapa.org/wp-content/uploads/2018/07/ EAPApaper_Asphalt_the\%20100\%20_recyclable_constructionproduct.pdf.

[4] R. Izaks, V. Haritonovs, I. Klasa, and M. Zaumanis, "Hot mix asphalt with high RAP content," Procedia Engineering, vol. 114, pp. 676-684, 2015.

[5] G. Liu, G. Leegwater, E. Nielsen, J. Komacka, and M. van de Ven, "Evaluating the rheological properties of PMB-containing RA binders from surface-layer asphalt mixtures to be recycled," Construction and Building Materials, vol. 49, pp. 8-14, 2013, ISSN 0950-0618.

[6] T. Koudelka and M. Varaus, "Asphalt mixtures with a high amount of RAP_case study," IOP Conference Series: Materials Science and Engineering, vol. 236, pp. 1-10, 2017.

[7] E. Hagos, M. Shirazi, and A. van de Wall, "The development of $100 \%$ RAP asphalt mixture with the use of innovative rejuvenator," in Proceedings of the 6th Eurasphalt \& Eurobitume Congress, Prague, Czech Republic, June 2016.

[8] A. M. Abu Abdo, "Utilizing reclaimed asphalt pavement (RAP) materials in new pavements-a review," International Journal of Thermal \& Environmental Engineering, vol. 12, no. 1, pp. 61-66, 2016.

[9] H. S. Jagadeesh and M. Kadayyanvarmath, "Studies on SMA mixes with partial rap replacement in addition with fiber," International Journal of Science and Research (IJSR), vol. 6, no. 8, pp. 65-73, 2017, ISSN (Online): 2319-7064.

[10] A. Liphardt, J. Król, and P. Radziszewski, "Influence of polymer modified binder content from RAP on stone mastic asphalt rutting resistance," Procedia Engineering, vol. 153, pp. 407-413, 2016.

[11] F. Perez, M. Rodriguez, J. De Visscher, A. Vanelstraete, and L. De Bock, "Design and performance of hot mix asphalts with high percentages of reclaimed asphalts: approach followed in the paramix project," in Proceedings of the 3rd Eurasphalt \& Eurobitume Congress, Vienna, Austria, May 2004.

[12] O. G. Andersson, A. Christiansen, U. Helk, L. Josephsen, H. F. Larsen, and E. Nielsen, "MUDP projekt: cirkulær asfalt produktion i Danmark," 2018, ISBN: 978-87-93710-95-5, https://www2.mst.dk/Udgiv/publikationer/2018/10/978-87-93 710-95-5.pdf.

[13] P. Coufalík, Rheological Properties of Asphalt Binders, Dissertation thesis, Brno University of Technology, Faculty of Civil Engineering, Brno, Czech Republic, 2017. 


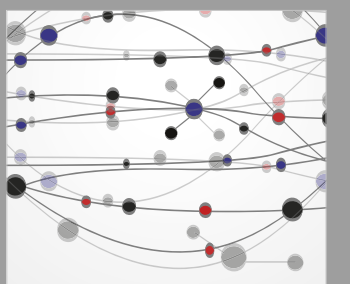

The Scientific World Journal
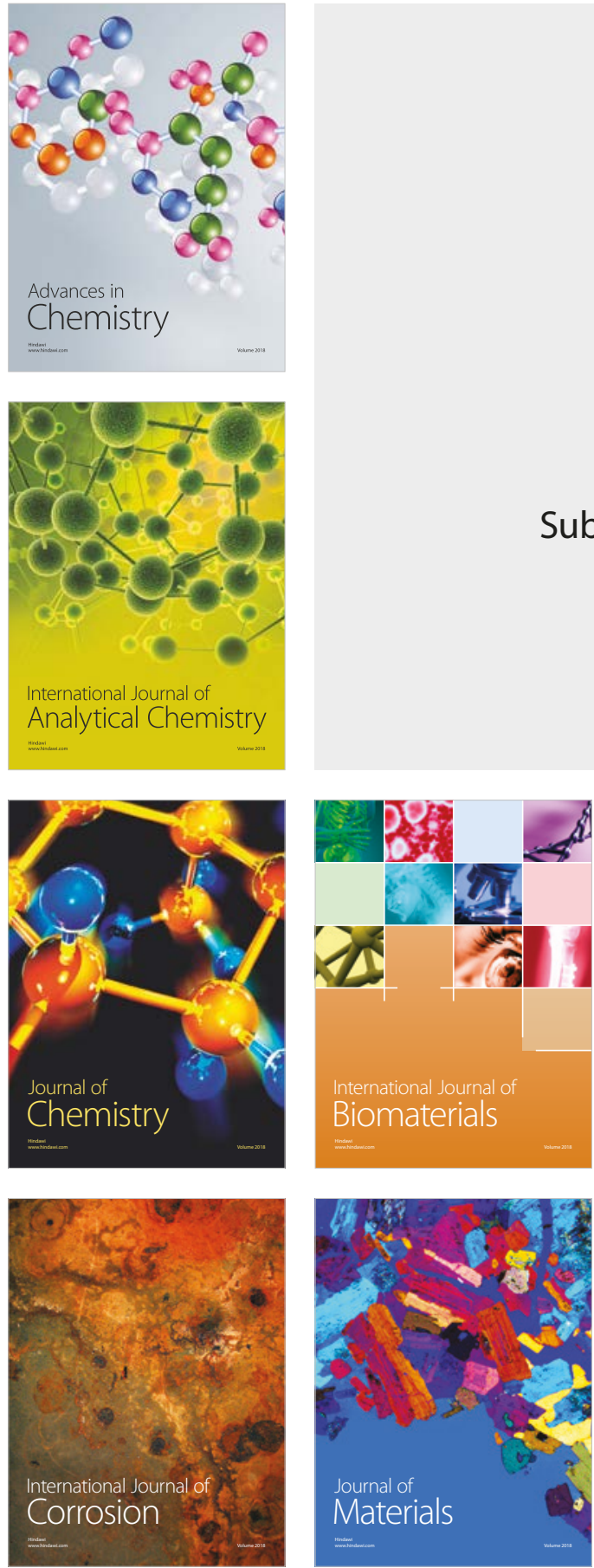

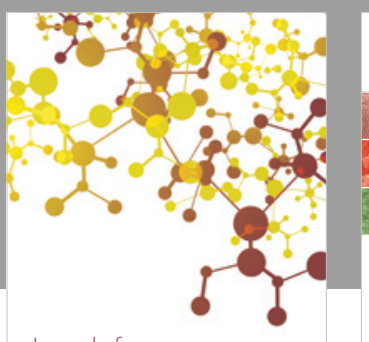

Journal of

Applied Chemistry
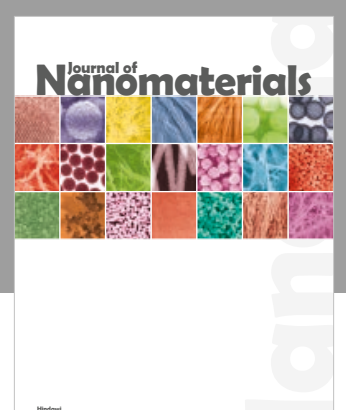

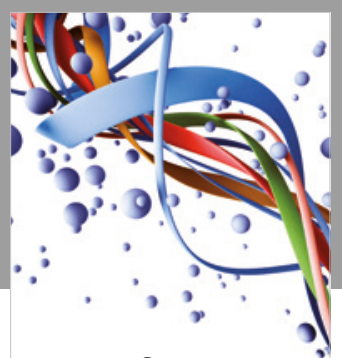

Scientifica

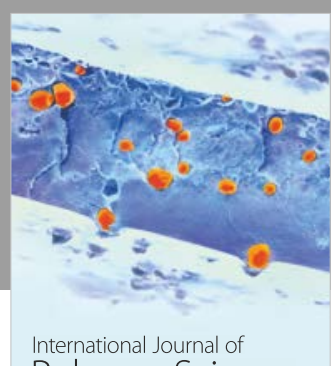

Polymer Science

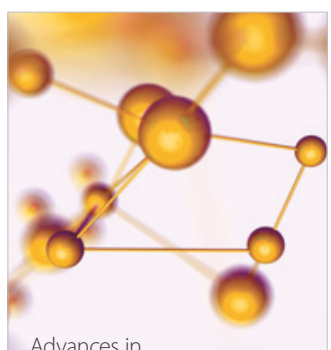

Physical Chemistry
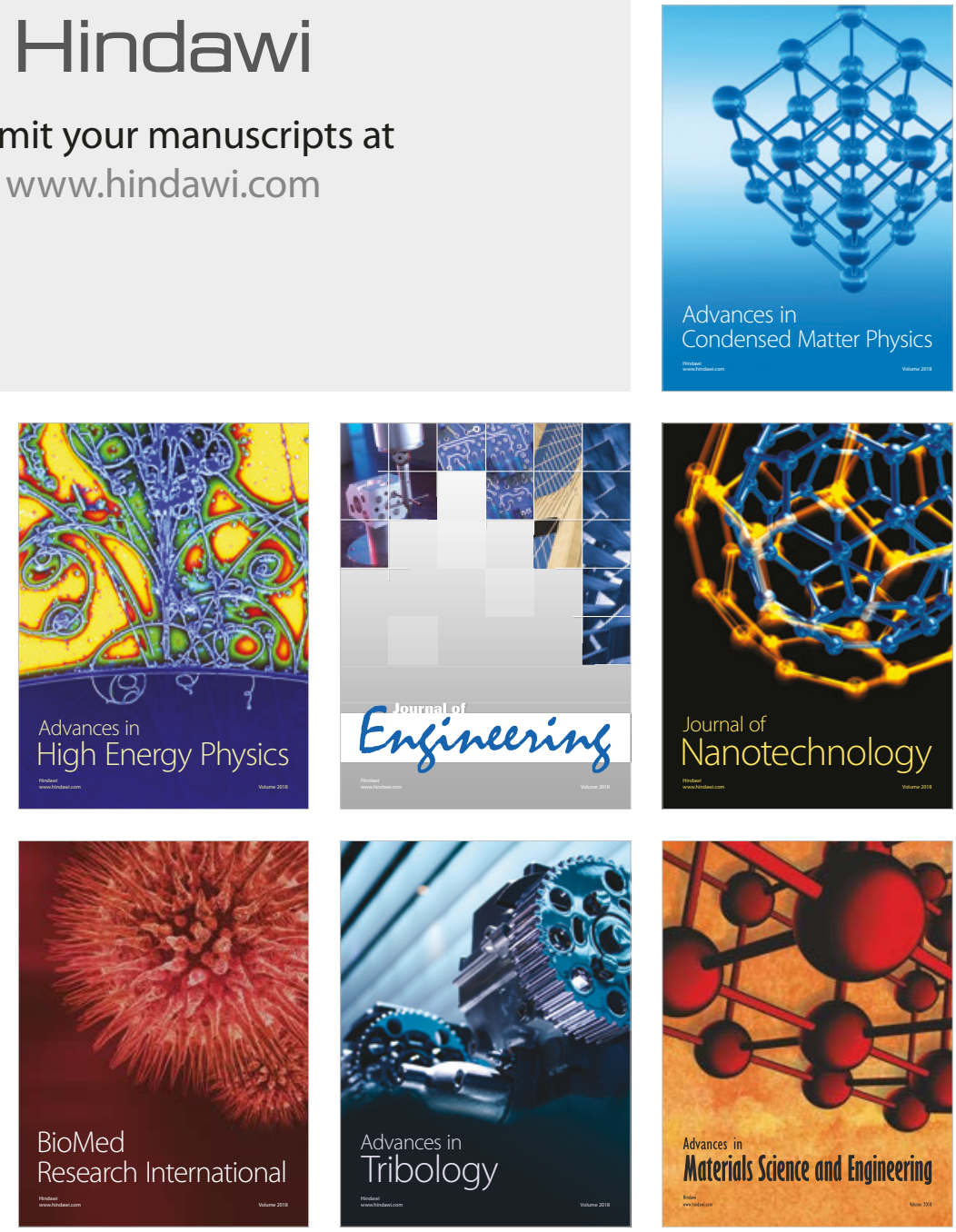